\title{
Need for weight management in Switzerland: findings from National Blood Pressure Week 2009
}

Thomas Volken*, René Schaffert and Peter Rüesch

\begin{abstract}
Background: The Swiss Health Survey (SHS) provides the only source of data for monitoring overweight and obesity in the general population in Switzerland. However, this survey reports body mass index (BMI) based on self-reported height and weight, and is therefore subject to measurement errors. Moreover, it is not possible to differentiate between overall and abdominal overweight. In this study, we aimed to gain a better understanding of the need for weight management in the general population of Switzerland by exploring and comparing prevalence rates of BMI and waist circumference (WC) based on physical measurements by trained observers, based on data from the 2009 National Blood Pressure Week (NBPW).
\end{abstract}

Methods: Sample selection was based on a one-stage cluster design. A total of 385 pharmacies representing 3,600 subjects were randomly selected from pharmacies participating in NBPW. BMI measures based on physical weight and height (NBPW) were compared with self-reported BMI measures from the SHS. BMI and WC measurements from NBPW were then used to produce population estimates of overweight and obesity.

Results: BMI-based overall prevalence of overweight and obesity was $43.6 \%$, which was $4.7 \%$ higher than the value based on the respective SHS data. Overweight and obesity were more common in men (54.3\%) than in women (33.5\%). However, the overall prevalence of increased WC in the general population was estimated to be $64.4 \%$, with more women (68.4\%) than men (60.1\%) exhibiting a WC above the threshold. The prevalence of subjects requiring weight management in the Swiss population remained high, even after adjusting WC for false positive and negative cases.

Conclusions: Firstly, it may be more appropriate for health promotion programs to address the wider group identified by WC, which includes subjects who need to reduce their weight, or gain no further weight. Secondly, the gender differences are reversed depending on the use of WC or BMI to identify subjects suitable for health promotion programs; more women than men are identified by WC, and more men than women using BMI. These differences should be accounted for in gender-specific health promotion programs.

\section{Background}

The Swiss Health Survey (SHS) currently provides the only source of data for monitoring overweight and obesity in the general population in Switzerland. The SHS was first conducted in 1992 and is repeated every five years. The 2007 sample included over 19,000 subjects, aged 15 years or older. Subjects were randomly selected within private households and computer-aided telephone interviews were conducted [1]. However, two potential problems exist. First, data on body mass index (BMI) is derived from self-reported weight and height;

\footnotetext{
* Correspondence: thomas.volken@zhaw.ch
Department of Health Professions, Zurich University of Applied Sciences,

* Correspondence: thomas.volken@zhaw.ch
Department of Health Professions, Zurich University of Applied Sciences, Winterthur, Switzerland
}

respondents tend to overestimate their height and underestimate their weight, leading to under-reporting of BMI values [2-8], with consequent underestimation of the prevalence of overweight and obesity. Second, the SHS only uses BMI as a measure of overweight and obesity; because abdominal fat mass can vary substantially within a narrow range of total body fat or BMI, other methods in addition to the measurement of BMI would help to identify individuals at risk from overweightrelated illnesses $[9,10]$. Empirical evidence suggests that waist circumference (WC) may be a better predictor of overweight-related illnesses than BMI [11-14], or should be used together with BMI $[10,15,16]$. 
Measures used in public health programs should be easy to administer and the results should be able to be translated into simple messages for the public. WC is both easy to administer and to explain.

Few studies have developed correction factors that can be applied to self-reported data to reduce the biases in BMIs $[2,17,18]$, and the results appear to be discouraging [7]. While such correction factors have been proposed for the BMI values reported in the SHS [2], there are currently no studies estimating the prevalence of subjects in the Swiss population in need of weight management based on WC. Neglecting the central fat distribution indicated by WC may lead to serious misclassification issues when identifying subjects who need to control their weight, because a considerable number of subjects with a low BMI may still have a WC and waist:hip ratio above the threshold [19]. Consequently, the Swiss prevalence figures for subjects in need of weight management and at risk of overweight-related illnesses may be biased.

The current study used BMI and WC data from National Blood Pressure Week (NBPW) 2009 to reduce both measurement and classification errors, and to provide an estimate of the prevalence of subjects in need of weight management in the Swiss population.

\section{Methods}

\section{Subject recruitment}

This study was based on the cross-sectional, descriptive data from the 2009 NBPW. NBPW formed part of a prevention initiative by the Swiss Heart Foundation. Between June $2^{\text {nd }}$ and June $10^{\text {th }} 2009,800$ pharmacies in the association of Swiss pharmacies, pharmaSuisse, offered a blood pressure check free of charge. Subjects 14 years and older were recruited on a walk-in basis (self-selection). The check included standardized measurements of blood pressure, BMI, and WC, and survey questions on medication, diet, physical activity and smoking. The NBPW and SHS data used for this study are openly available for scientific use and can be obtained through the regular distribution channels of the Federal Bureau of Statistics and the Federal Office of Public Health.

\section{Anthropometric measurements}

All potential measurers received rudimentary training prior to performing the field study. This training consisted of a self-study manual providing detailed instructions on measurement procedures. Upon completion of the training, potential measurers had to pass a formal multiple-choice test to be accepted for the field work.

For the measurement procedures, all participating subjects were asked to remove their shoes and heavy outer garments (jackets, coats, jerseys, etc.). Their waist was measured using a non-stretchable tape over the lightly dressed abdomen, midway between the lowest rib and the iliac crest. Body height was measured using a stadiometer or measuring rod. Body weight was measured using calibrated scales. The large number of participating pharmacies meant that it was impossible to use the same equipment at every measurement site. Subjects were identified as overweight/obese (BMI $\geq$ $25.0 \mathrm{~kg} / \mathrm{m}^{2}$ ) according to World Health Organization references [9]. $\mathrm{WC} \geq 94.0 \mathrm{~cm}$ in men and $\geq 80.0 \mathrm{~cm}$ in women were taken as markers of central obesity $[9,20]$. Subjects were defined as being in need of weight management if they exceeded their respective WC thresholds, and were identified as needing to reduce weight, or gain no further weight [19].

\section{Study population and sampling}

No sampling frame for subjects participating in the NBPW was available, and economic constraints limited the number of questionnaires that could be collected from the 800 pharmacies for subsequent data entry and analyses. One-stage cluster sampling was therefore used. A total of 385 pharmacies with a total of 3,600 subjects was randomly selected from the participating pharmacies. For the purpose of this study, the initial sample was further narrowed down to include only subjects 18 years old or older, and for whom a full set of anthropometric data was available. This left 380 pharmacies and 3,170 subjects. Comparisons with national census and cross-sectional SHS 2007 data (Table 1) suggest that subjects participating in the NBPW are more likely to be female $(68 \%, \mathrm{p} \leq 0.001)$ and that both participating males (59.5 years, $\mathrm{p} \leq 0.001)$ and females (57.4 years, $\mathrm{p} \leq 0.001)$ tend to be older than the target Swiss population. The gender difference may reflect the traditional gender-specific division of labour (with women being more likely to do the daily shopping), and the fact that subjects participating in the NBPW are older (female: 6.1 years, male: 9.9 years) may reflect the increased

Table 1 Average age, BMI and WC by gender in the SHS and NBPW samples*

\begin{tabular}{lcccc}
\hline & \multicolumn{2}{c}{ SHS } & \multicolumn{2}{c}{ NBPW } \\
\hline \multirow{2}{*}{ variable } & male & female & male & female \\
& $n=8,017$ & $n=9,862$ & $n=1,015$ & $n=2,155$ \\
\hline age (years) & $44.8 \%$ & $55.2 \%$ & $32 \%$ & $68 \%$ \\
\hline BMI (kg/m2) & 49.6 & 51.3 & 59.5 & 57.4 \\
& $(17.2)$ & $(17.9)$ & $(15.1)$ & $(17.0)$ \\
WC (cm) & 25.4 & 23.7 & 26.2 & 24.5 \\
& $(3.6)$ & $(4.3)$ & $(3.7)$ & $(4.3)$ \\
& - & - & 98.8 & 88.0 \\
& & & $(11.3)$ & $(12.4)$ \\
\hline
\end{tabular}

*Age, BMI and WC were based on unweighted arithmetic means. Source: National Blood Pressure Week 2009, pharmaSuisse. 
probability of developing disease with increasing age. However, this does not necessarily mean that sicker people are more likely to go to a pharmacy in any given week, because shopping can easily be done by proxy. Nevertheless, the locations of the data collection points and the self-selection of participating subjects in the pharmacies may represent potential sources of bias.

\section{Design effects}

The design effects [21] resulting from one-stage cluster sampling (Table 2) amounted to an average of 1.8 (BMI), 1.9 (WC) and 2.0 (WC $\geq 94(80)$ ). In general, the average design effects for men were almost three times as large as those for women, because the sample size for men was much smaller $(n=1,015)$ than that for women ( $\mathrm{n}=2,155)$. Furthermore, the sample sizes for the 18-29 ( $\mathrm{n}=34)$ and 30-39 $(\mathrm{n}=64)$ age groups were particularly small.

\section{Weighting, classification and adjustment of data}

Data were standardized, i.e., weighted by post-stratification adjustment factors [22] including gender and age, to represent the Swiss population in 2007, with the exception of the sparsely populated cantons Uri and Appenzell Innerrhoden, which did not participate in the NBPW. The total population represented by the NBPW sample amounts to $6,103,469$ inhabitants, compared to $6,143,378$ inhabitants in all cantons.

Subjects were classified as being in need of weight management if their WC exceeded the threshold value. The sensitivity and specificity figures reported by Lean, Han and Morrison [19] were used to account for false

Table 2 Design effects for BMI, WC and WC above threshold NBPW 2009*

\begin{tabular}{|c|c|c|c|c|}
\hline type of estimate & $\begin{array}{l}\text { average } \\
\text { DEFF }\end{array}$ & $\begin{array}{c}\max \\
\text { DEFF }\end{array}$ & $\min _{\text {DEFF }}$ & $\begin{array}{c}\text { average } \\
\text { DEFT }\end{array}$ \\
\hline \multicolumn{5}{|l|}{ BMI } \\
\hline $\begin{array}{l}\text { male \& } \\
\text { female }\end{array}$ & 1.8 & 9.3 & 0.4 & 1.2 \\
\hline female & 1.0 & 2.0 & 0.4 & 1.0 \\
\hline male & 2.7 & 9.3 & 0.6 & 1.5 \\
\hline \multicolumn{5}{|l|}{ WC } \\
\hline $\begin{array}{l}\text { male \& } \\
\text { female }\end{array}$ & 1.9 & 9.8 & 0.5 & 1.2 \\
\hline female & 1.1 & 2.1 & 0.5 & 1.0 \\
\hline male & 2.7 & 9.8 & 0.6 & 1.5 \\
\hline \multicolumn{5}{|l|}{$W C>=94(80)$} \\
\hline $\begin{array}{l}\text { male \& } \\
\text { female }\end{array}$ & 2.0 & 9.4 & 0.5 & 1.3 \\
\hline female & 1.1 & 1.8 & 0.5 & 1.0 \\
\hline male & 2.9 & 9.4 & 0.8 & 1.5 \\
\hline
\end{tabular}

${ }^{*}$ Average DEFF (design effect) and DEFT (square root of design effect) values are grand means based on the arithmetic means of the age and gender groups. Source: National Blood Pressure Week 2009, pharmaSuisse. positive and false negative cases: female subjects with a WC above the threshold were weighted with an adjustment factor (sensitivity) of 0.965 (true positive) and 1-0.965 (false positive), while male subjects were weighted with 0.968 and 1-0.968, respectively. Subjects below the critical WC threshold were weighted accordingly using the above specificity figures (female: 0.983, male: 0.982). Following Lean and colleagues, the prevalence rates for subjects in need of weight management, after adjusting for misclassification, reflected the combined prevalence of concordant cases identified by BMI and WC above the thresholds, as well as discordant cases having a BMI below the threshold, but a waist:hip ratio $\geq$ 0.95 (men) or $\geq 0.80$ (women) (Figure 1). Most subjects with a high WC and a BMI below the cut-off also have a high waist:hip ratio, thus justifying weight management, while subjects with a BMI above and a WC below the thresholds have low waist:hip ratios [19].

\section{Statistical analyses}

Statistical analyses were based on frequency tables; differences between categories were assessed using the design-based F-test, which is an F approximation to the second-order Rao-Scott Chi-squared statistics [23-25]. Statistical analyses also included a calculation of crude prevalence rates for overweight and obesity and increased WC by age group and gender. The resulting BMI values were compared with BMI data based on the SHS to assess the plausibility of the NBPW data. Two sample Student's $t$-tests with variance corrected for the design effect were used to assess BMI differences between the two surveys. To incorporate information on the appropriate weights and sampling units for correct variance estimation, all statistical analyses of the NBPW data were carried out using Stata's command for complex surveys ("svy prefix"). Statistical significance was established at $\mathrm{p}<0.05$.

\section{Results \\ Self-reported and measured BMI}

The population-corrected average BMI values based on height and weight measured by trained observers in the pharmacies were consistently higher than the BMI values based on self-reported weight and height over all age groups and both genders (Tables 3 and 4 ). The arithmetic mean of measured BMI was $24.0 \mathrm{~kg} / \mathrm{m}^{2}$ for women and $25.8 \mathrm{~kg} / \mathrm{m}^{2}$ for men, while the self-reported values were $23.6 \mathrm{~kg} / \mathrm{m}^{2}$ and $25.3 \mathrm{~kg} / \mathrm{m}^{2}$, respectively ( $\mathrm{p}<0.001$ for both men and women). The trajectory of mean BMI displayed a similar pattern over all age categories using either data source. BMI in women tended to be higher in older age cohorts, and the mean BMI was lower than in the preceding group only in the oldest age category ( $\geq 80$ years). The BMI pattern was similar 


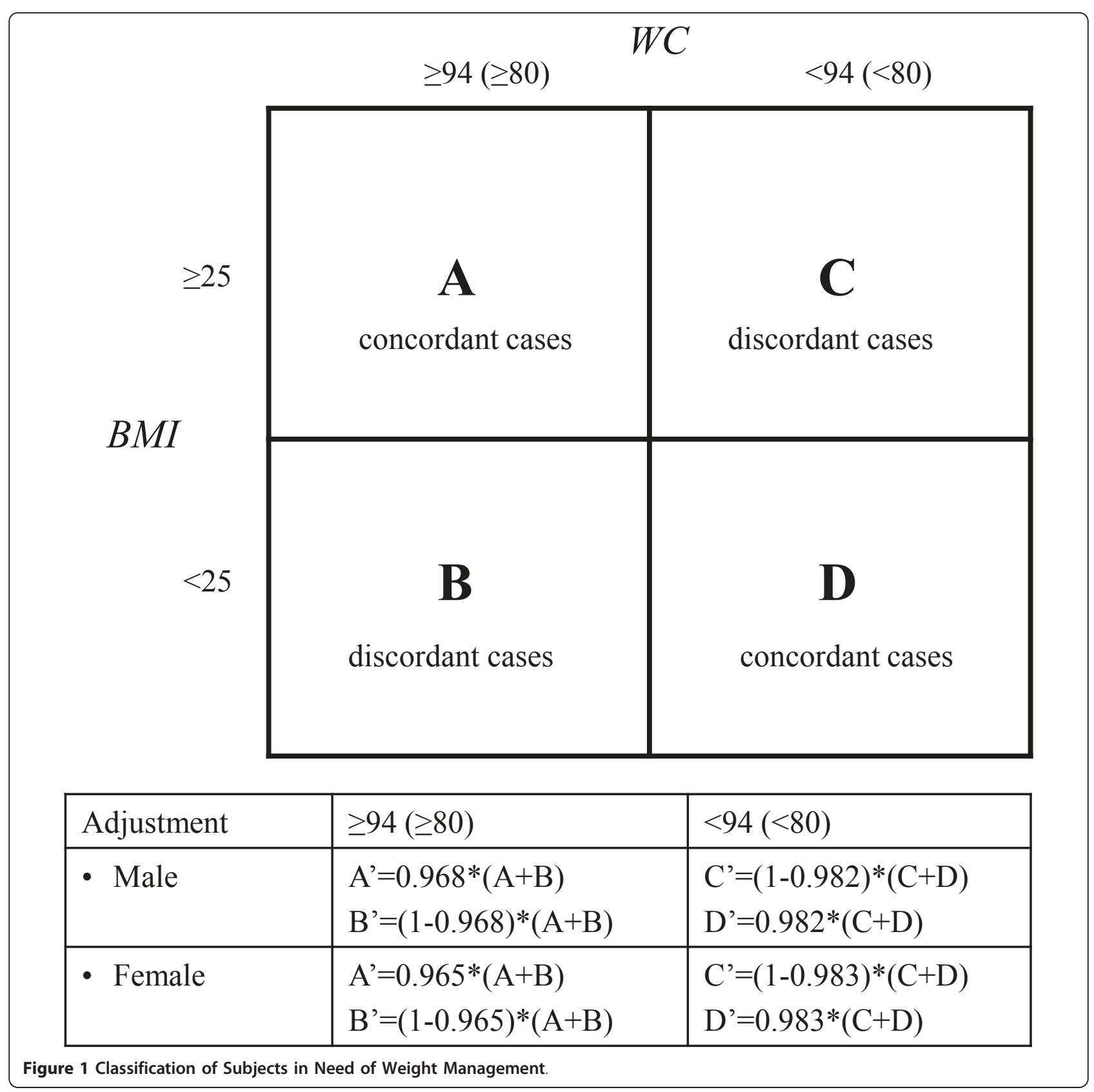

in men; however, a fall in average BMI was already achieved in the 70-79-year-old group, and the fall was greater in the oldest age category.

Self-reported average BMI values based on the SHS were significantly lower than average BMI values based on NBPW data in nine of the 14 age and gender groups (Table 3).

\section{Overweight and obesity and increased WC}

Tables 5 and 6 summarize the prevalence of overweight and obesity $\left(\mathrm{BMI} \geq 25.0 \mathrm{~kg} / \mathrm{m}^{2}\right)$ and the prevalence of central obesity above the threshold $(\mathrm{WC} \geq 94.0 \mathrm{~cm}$ in men and $\mathrm{WC} \geq 80.0 \mathrm{~cm}$ in women). Consistent with the above findings, the estimated prevalence of overweight and obesity in Switzerland based on measured NBPW BMI values was higher than that based on SHS data. The overall prevalence of overweight and obesity was $43.6 \%$, which was $4.7 \%$ higher $(\mathrm{p}<0.001)$ than the figure based on the respective SHS data (men: $+5.8 \%$, p < 0.001 ; women: $+3.7 \%, \mathrm{p}<0.001)$. Overweight and obesity was more common in men $(54.3 \%)$ than in women (33.5\%; $\mathrm{p}<0.001)$. However, the overall prevalence of increased $\mathrm{WC}$ in the general population was estimated to be $64.4 \%$. More women (68.4\%) than men $(60.1 \%$; p < 
Table 3 Average BMIs SHS 2007

\begin{tabular}{|c|c|c|c|c|c|}
\hline & age & $\mathrm{n}$ & $\mathrm{N}$ & BMI & $95 \% \mathrm{Cl}$ \\
\hline \multirow[t]{7}{*}{ female } & $18-29$ & 1,214 & 564,162 & $21.7^{*}$ & $21.5-21.9$ \\
\hline & 30-39 & 1,762 & 572,102 & 23.1 & 22.8-23.3 \\
\hline & $40-49$ & 1,820 & 630,493 & $23.3^{* * *}$ & $23.0-23.5$ \\
\hline & $50-59$ & 1,572 & 500,548 & 24.3 & $24.0-24.5$ \\
\hline & $60-69$ & 1,642 & 420,054 & $24.8^{*}$ & $24.5-25.0$ \\
\hline & $70-79$ & 1,225 & 297,687 & 25.3 & $25.0-25.6$ \\
\hline & $>=80$ & 627 & 159,492 & $24.3^{*}$ & $23.9-24.7$ \\
\hline \multirow[t]{7}{*}{ male } & $18-29$ & 1,079 & 576,393 & $23.5^{*}$ & 23.3-23.8 \\
\hline & 30-39 & 1,455 & 548,201 & $25.0^{* * *}$ & $24.7-25.2$ \\
\hline & $40-49$ & 1,687 & 627,945 & $25.7^{* *}$ & $25.5-25.9$ \\
\hline & $50-59$ & 1,311 & 501,934 & $26.1^{* *}$ & 25.8-26.4 \\
\hline & $60-69$ & 1,277 & 405,718 & $26.4^{*}$ & $26.1-26.6$ \\
\hline & 70-79 & 849 & 240,490 & 26.0 & 25.6-26.4 \\
\hline & $>=80$ & 359 & 98,160 & 25.4 & $25.0-25.8$ \\
\hline total & & 17,879 & $6,143,378$ & $24.4^{* * *}$ & $24.3-24.5$ \\
\hline female & & 9,862 & $3,144,538$ & $23.6^{* * *}$ & 23.4-23.7 \\
\hline male & & 8,017 & $2,998,840$ & $25.3^{* * *}$ & $25.2-25.4$ \\
\hline
\end{tabular}

${ }^{1} \mathrm{n}$ : number of subjects in the sample; $\mathrm{N}$ : estimated number of subjects in the Swiss population; BMI: body mass index $\mathrm{kg} / \mathrm{m}^{2}$; Cl: confidence intervals. All BMI figures are population corrected (weighted) and are based on arithmetic means within age and gender groups. SHS BMI was calculated using selfreported height and weight, asterisks denote significant group differences between average SHS BMls and their corresponding NBPW BMls (see Table 4). ${ }^{*} \mathrm{p}<0.05$; ${ }^{* *} \mathrm{p}<0.01$; ${ }^{* * *} \mathrm{p}<0.001$. Source: Swiss Health Survey 2007, Federal Office of Public Health.

Table 4 Average BMIs NBPW 2009*

\begin{tabular}{|c|c|c|c|c|c|}
\hline & age & $n$ & $\mathrm{~N}$ & BMI & $95 \% \mathrm{Cl}$ \\
\hline \multirow[t]{7}{*}{ female } & $18-29$ & 194 & 551,065 & 22.2 & $21.7-22.6$ \\
\hline & $30-39$ & 146 & 547,343 & 23.2 & $22.6-23.8$ \\
\hline & $40-49$ & 312 & 610,493 & 24.3 & $23.8-24.9$ \\
\hline & $50-59$ & 420 & 493,190 & 24.4 & $23.9-24.8$ \\
\hline & $60-69$ & 508 & 406,797 & 25.0 & $24.6-25.4$ \\
\hline & $70-79$ & 394 & 301,560 & 25.4 & $24.9-25.9$ \\
\hline & $>=80$ & 181 & 232,027 & 24.7 & $24.1-25.2$ \\
\hline \multirow[t]{7}{*}{ male } & $18-29$ & 34 & 558,698 & 23.8 & $22.5-25.2$ \\
\hline & $30-39$ & 64 & 545,221 & 26.1 & $25.3-26.8$ \\
\hline & $40-49$ & 160 & 621,985 & 26.1 & $25.6-26.7$ \\
\hline & $50-59$ & 204 & 495,701 & 26.5 & $25.9-27.1$ \\
\hline & $60-69$ & 272 & 384,989 & 26.6 & $26.1-27.0$ \\
\hline & $70-79$ & 196 & 234,820 & 26.3 & $25.8-26.8$ \\
\hline & $>=80$ & 85 & 119,580 & 25.5 & $24.8-26.2$ \\
\hline total & & 3,170 & $6,103,469$ & 24.9 & $24.6-25.1$ \\
\hline female & & 2,155 & $3,142,475$ & 24.0 & $23.7-24.2$ \\
\hline male & & 1,015 & $2,960,994$ & 25.8 & $25.4-26.2$ \\
\hline
\end{tabular}

${ }^{*} \mathrm{n}$ : number of subjects in the sample; $\mathrm{N}$ : estimated number of subjects in the Swiss population; BMl: body mass index $\mathrm{kg} / \mathrm{m}^{2}$; Cl: confidence intervals. All BMI figures are population corrected (weighted) and are based on arithmetic means within age and gender groups. NBPW BMI was calculated using physical measurements of height and weight. Source: National Blood Pressure Week 2009, pharmaSuisse.
Table 5 Prevalence of overweight and obesity SHS 2007*

\begin{tabular}{|c|c|c|c|c|}
\hline \multicolumn{5}{|c|}{$\mathrm{BMI} \geq 25$} \\
\hline & age & $\mathrm{N}$ & $\%$ & $95 \% \mathrm{Cl}$ \\
\hline \multirow[t]{7}{*}{ female } & $18-29$ & 70,394 & 12.5 & $10.4-15.0$ \\
\hline & 30-39 & 130,732 & 22.9 & $20.5-25.3$ \\
\hline & $40-49$ & 162,384 & 25.8 & $23.2-28.5$ \\
\hline & 50-59 & 187,396 & 37.4 & $34.4-40.6$ \\
\hline & $60-69$ & 177,066 & 42.2 & $39.1-45.2$ \\
\hline & 70-79 & 147,086 & 49.4 & 45.9-53.0 \\
\hline & $>=80$ & 61,850 & 38.8 & $34.2-43.6$ \\
\hline \multirow[t]{7}{*}{ male } & $18-29$ & 155,242 & 26.9 & $23.7-30.5$ \\
\hline & 30-39 & 236,274 & 43.1 & $40.0-46.2$ \\
\hline & $40-49$ & 337,913 & 53.8 & $50.8-56.8$ \\
\hline & $50-59$ & 284,703 & 56.7 & $53.2-60.1$ \\
\hline & $60-69$ & 254,060 & 62.6 & 59.3-65.8 \\
\hline & $70-79$ & 132,376 & 55.0 & $51.0-59.1$ \\
\hline & $>=80$ & 54,414 & 55.4 & $49.3-61.4$ \\
\hline total & & $2,391,889$ & 38.9 & 38.0-39.9 \\
\hline female & & 936,908 & 29.8 & $28.7-31.0$ \\
\hline male & & $1,454,981$ & 48.5 & $47.1-49.9$ \\
\hline
\end{tabular}

* N : estimated number of subjects with $\mathrm{BMI} \geq 25$; \%: estimated prevalence of $\mathrm{BMI} \geq 25 ; \mathrm{Cl}$ : confidence intervals. All figures are population corrected

(weighted). Source: Swiss Health Survey 2007, Federal Office of Public Health.

Table 6 Prevalence of overweight and obesity and increased WC NBPW 2009*

\begin{tabular}{|c|c|c|c|c|c|c|c|}
\hline & \multicolumn{3}{|c|}{$\mathrm{BMI} \geq 25$} & \multicolumn{4}{|c|}{$W C \geq 94(80)$} \\
\hline & age & $\mathbf{N}$ & $\%$ & $95 \% \mathrm{Cl}$ & $\mathrm{N}$ & $\%$ & $95 \% \mathrm{Cl}$ \\
\hline \multirow[t]{7}{*}{ female } & $18-29$ & 99,419 & 18.0 & $13.2-24.2$ & 258,489 & 46.9 & $38.5-55.6$ \\
\hline & 30-39 & 146,208 & 26.7 & $20.1-34.5$ & 326,156 & 59.6 & $51.5-67.2$ \\
\hline & $40-49$ & 219,151 & 35.9 & $30.6-41.6$ & 418,736 & 68.6 & 62.9-73.8 \\
\hline & $50-59$ & 170,268 & 34.5 & 29.7-39.7 & 360,498 & 73.1 & $68.5-77.2$ \\
\hline & $60-69$ & 177,773 & 43.7 & $39.7-47.8$ & 327,520 & 80.5 & 76.5-84.0 \\
\hline & $70-79$ & 146,953 & 48.7 & $43.5-54.0$ & 255,637 & 84.8 & 80.9-88.0 \\
\hline & $>=80$ & 92,298 & 39.8 & $33.0-47.0$ & 203,825 & 87.9 & $82.3-91.8$ \\
\hline \multirow[t]{7}{*}{ male } & 18-29 & 197,188 & 35.3 & $20.0-54.3$ & 197,188 & 35.3 & 20.0-54.3 \\
\hline & 30-39 & 323,725 & 59.4 & $47.7-70.1$ & 332,244 & 60.9 & $49.7-71.2$ \\
\hline & $40-49$ & 334,317 & 53.8 & $46.3-61.1$ & 361,529 & 58.1 & $50.5-65.4$ \\
\hline & $50-59$ & 298,879 & 60.3 & $52.9-67.3$ & 320,748 & 64.7 & $57.5-71.3$ \\
\hline & $60-69$ & 256,188 & 66.5 & $60.6-72.0$ & 287,326 & 74.6 & 69.1-79.5 \\
\hline & $70-79$ & 142,569 & 60.7 & $53.8-67.2$ & 185,700 & 79.1 & $73.1-84.0$ \\
\hline & $>=80$ & 53,459 & 44.7 & $34.6-55.3$ & 95,664 & 80.0 & $69.0-87.8$ \\
\hline total & & $2,658,395$ & 43.6 & $40.5-46.7$ & $3,931,259$ & 64.4 & $60.8-67.9$ \\
\hline female & & $1,052,071$ & 33.5 & $30.8-36.3$ & $2,150,861$ & 68.4 & $65.2-71.5$ \\
\hline male & & $1,606,324$ & 54.3 & 48.9-59.6 & $1,780,398$ & 60.1 & 54.4-65.6 \\
\hline
\end{tabular}

* N: estimated number of subjects with $B M I \geq 25$ and $W C \geq 94(80)$ respectively; $\%$ : estimated prevalence of $\mathrm{BMI} \geq 25$ and $\mathrm{WC} \geq 94(80)$ respectively; $\mathrm{Cl}$ : confidence intervals; WC: waist circumference. All figures are population corrected (weighted). Sources: National Blood Pressure Week 2009, pharmaSuisse \& Swiss Heart Foundation; Swiss Health Survey 2007, Federal Office of Public Health. 
0.001) exhibited a waist circumference above the threshold. Unlike the prevalence of overweight and obesity, which decreased in the oldest (female) or two oldest age categories (male), the prevalence of above-threshold WC increased almost uniformly with increasing age, and reached $\geq 80 \%$ in both genders.

\section{Subjects in need of weight management}

Almost three quarters of the cases exhibited a concordant pattern with regard to BMI and WC (Table 7), i.e., both their BMI and WC were either above $(40.7 \%)$ or below the thresholds (32.8\%). Almost half of the men (48.6\%) and one third of the women (33.3\%) exceeded both threshold values, with markedly more men than women falling into this category $(\mathrm{p}<0.001)$. In contrast, there was no significant gender difference in cases with $\mathrm{BMI}$ and WC both below the threshold values (female $31.3 \%$; male $34.3 \%$; $\mathrm{p}>0.3$ ). Both discordant categories showed significant gender differences; substantially more women (35.2\%) than men (11.5\%) had BMIs below and WCs above the threshold values $(\mathrm{p}<0.001)$, while more men $(5.6 \%)$ than women $(0.2 \%)$ had BMIs above and WCs below the threshold values $(\mathrm{p}<0.001)$. Overall, subjects with discordant threshold values accounted for $26.5 \%$ of the total population. However, approximately $90 \%$ of these cases were accounted for by having BMIs below and WCs above threshold values (23.7\%), and little more than $10 \%$ were accounted for by the converse situation (2.8\%).

The adjusted prevalence rates for subjects in need of weight management are given in Table 8. Essentially, this reflects the combined weighted prevalence of

Table 7 Prevalence of subjects in BMI and WC categories below and above threshold for weight management*

\begin{tabular}{|c|c|c|c|c|c|c|}
\hline & \multicolumn{2}{|c|}{ female } & \multicolumn{2}{|c|}{ male } & \multicolumn{2}{|c|}{ total } \\
\hline & $\begin{array}{l}\% \\
(\mathbf{N})\end{array}$ & $95 \% \mathrm{Cl}$ & $\begin{array}{l}\% \\
\text { (N) }\end{array}$ & $95 \% \mathrm{Cl}$ & $\begin{array}{l}\% \\
\text { (N) }\end{array}$ & $95 \% \mathrm{Cl}$ \\
\hline $\mathrm{BMI} \geq 25$ & 33.3 & $30.5-36.1$ & 48.6 & $43.5-53.8$ & 40.7 & $37.7-43.9$ \\
\hline$W C \geq 94(80)$ & \multicolumn{2}{|c|}{$(1,045,299)$} & \multicolumn{2}{|c|}{$(1,439,830)$} & \multicolumn{2}{|c|}{$(2,485,129)$} \\
\hline BMI $<25$ & 35.2 & $32.6-37.8$ & 11.5 & $9.3-14.1$ & 23.7 & $21.7-25.9$ \\
\hline$W C \geq 94(80)$ & \multicolumn{2}{|c|}{$(1,105,563)$} & \multicolumn{2}{|c|}{$(340,568)$} & \multicolumn{2}{|c|}{$(1,446,130)$} \\
\hline BMI < 25 & 31.3 & $28.4-34.5$ & 34.3 & $28.6-40.3$ & 32.8 & $29.3-36.4$ \\
\hline WC < $94(80)$ & \multicolumn{2}{|c|}{$(984,841)$} & \multicolumn{2}{|c|}{$(1,014,102)$} & \multicolumn{2}{|c|}{$(1,998,944)$} \\
\hline $\mathrm{BMI} \geq 25$ & 0.2 & $0.1-0.6$ & 5.6 & $4.2-7.6$ & 2.8 & $2.1-3.8$ \\
\hline WC < $94(80)$ & $(6,772)$ & & $(166,4$ & & $(173,26$ & \\
\hline \multirow[t]{2}{*}{ total } & \multirow{2}{*}{\multicolumn{2}{|c|}{$\begin{array}{l}100 \\
(3,142,475)\end{array}$}} & \multicolumn{2}{|l|}{100} & \multicolumn{2}{|c|}{100} \\
\hline & & & \multicolumn{2}{|c|}{$(2,960,994)$} & \multicolumn{2}{|c|}{$(6,103,469)$} \\
\hline
\end{tabular}

\footnotetext{
* $\mathrm{N}$ : estimated number of subjects in BMI/WC category; \%: estimated prevalence of subjects in BMI/WC category in the Swiss population; $\mathrm{Cl}$ : confidence intervals; WC: waist circumference. All values are population corrected (weighted). All BMI and WC values are based on arithmetic means within groups; BMI and WC were calculated using physical measurements of height and weight and waist circumference. Sources: National Blood Pressure Week 2009, pharmaSuisse \& Swiss Heart Foundation.
}

Table 8 Adjusted prevalence of subjects in need of weight management NBPW 2009

\begin{tabular}{|c|c|c|c|c|}
\hline & Age & $\mathrm{N}$ & $\%$ & $95 \% \mathrm{Cl}$ \\
\hline \multirow[t]{7}{*}{ female } & $18-29$ & 249,442 & 44.2 & $35.9-52.9$ \\
\hline & 30-39 & 314,741 & 56.9 & 48.8-64.8 \\
\hline & $40-49$ & 404,080 & 66.2 & $60.4-71.6$ \\
\hline & 50-59 & 347,881 & 70.9 & $66.1-75.3$ \\
\hline & $60-69$ & 316,056 & 78.8 & $74.5-82.5$ \\
\hline & 70-79 & 246,690 & 83.3 & $79.2-86.8$ \\
\hline & $>=80$ & 196,691 & 86.6 & 80.6-91.0 \\
\hline \multirow[t]{7}{*}{ male } & $18-29$ & 190,878 & 33.5 & 18.8-52.3 \\
\hline & 30-39 & 321,612 & 59.0 & $47.7-69.5$ \\
\hline & $40-49$ & 349,960 & 56.2 & $48.5-63.5$ \\
\hline & $50-59$ & 310,484 & 62.9 & 55.6-69.6 \\
\hline & $60-69$ & 278,132 & 73.1 & $67.4-78.1$ \\
\hline & 70-79 & 179,757 & 77.7 & $71.5-82.9$ \\
\hline & $>=80$ & 92,603 & 78.7 & $67.2-86.9$ \\
\hline total & & $3,799,006$ & 62.2 & $58.5-65.8$ \\
\hline female & & $2,075,581$ & 66.1 & $62.7-69.2$ \\
\hline male & & $1,723,425$ & 58.2 & $52.4-63.8$ \\
\hline
\end{tabular}

* $\mathrm{N}$ : estimated number of subjects in need for weight management [adjusted WC $\geq 94(80)]$; \%: estimated prevalence of subjects in need for weight management in the Swiss population; $\mathrm{Cl}$ : confidence intervals. All figures are population corrected (weighted). Sources: National Blood Pressure Week 2009, pharmaSuisse \& Swiss Heart Foundation; Swiss Health Survey 2007, Federal Office of Public Health.

concordant cases with BMI and WC both above threshold values, and of weighted discordant cases (for details, see Methods). The need for weight management in Switzerland is thus determined to be high, with $62.2 \%$ of the Swiss population requiring weight management, representing fewer men (58.2\%) than women (66.1\%) who need to reduce their weight, or at least gain no more weight $(\mathrm{p}<0.001)$. The need for weight management is generally more prevalent in older age cohorts. However, the age-related increase of prevalence rates is more uniform in women, in contrast to a slight drop in the need for weight management in 40-49-year-old men, compared to the preceding age cohort.

\section{Discussion}

BMI values based on SHS and NBPW data are both potentially subject to biases; however, the sources of these biases may be quite different. On the one hand, the self-reported nature of the SHS BMI data almost certainly include measurement errors due to factors such as the lack of standardized measurement instruments and procedures, respondents' knowledge about and recollection of their actual height and weight, response acquiescence, and social desirability [4,26-29]. On the other hand, measured NBPW measures of BMI and WC may be biased due to the self-selection of 
participating pharmacies and/or subjects, or the varying brands and qualities of the measurement equipment used [30]. A further limiting factor of this study may be its specific sample design. The average design effect was quite large, which may represent a problem in the case of male age cohorts with small sample sizes. However, despite the different sources of measurement errors and biases, there were substantial similarities between selfreported and measured BMI, and our findings were generally consistent with previously reported studies, which lend plausibility to the newly collected NBPW data. Firstly, the average BMI trajectory showed a similar pattern over all age categories for males and females using both data sources. BMI is generally higher in older age cohorts, and decreases again only in the highest age categories [31]. Secondly, measured BMI was consistently higher than self-reported BMI, which is a welldocumented phenomenon in the research literature $[3,5-7,28,32]$, though the difference was only significant in nine out of the 14 age and gender groups. Thirdly, average differences between measured and self-reported BMI values were similar in women $\left(0.34 \mathrm{~kg} / \mathrm{m}^{2}\right)$ and men $\left(0.37 \mathrm{~kg} / \mathrm{m}^{2}\right)$, contrary to the thesis suggesting that gender-specific differences exist in terms of self-declaration of weight and height, i.e., the idea that women may be more prone to report weights or heights to conform to socially constructed body images $[5,29,33]$. Not surprisingly, the estimated prevalence of overweight and obesity (BMI $\geq 25.0 \mathrm{~kg} / \mathrm{m}^{2}$ ) in the Swiss population was significantly higher when based on NBPW BMI values (43.6\%), compared to SHS values (38.9\%), and the magnitude of the increase $(4.7 \%$; $p<0.001)$ was comparable with that in previous studies that assessed self-reported versus clinical measurements of BMI [6]. The prevalence of increased WC was even higher (64.4\%). However, we found that the prevalence of overweight and obesity defined by BMI was higher in men (54.3\% versus $33.5 \%$; $\mathrm{p}<0.001)$, whereas the prevalence of an increased WC was higher in women $(68.4 \%$ versus $60.1 \%$; $p<0.001)$ $[13,34,35]$. These findings have important implications. Firstly, prevalence figures for the population at risk of overweight and obesity and overweight-related illnesses based on SHS BMI data potentially understate the problem. Secondly, these prevalence figures are genderbiased. Only $25.1 \%$ of men with BMI below the threshold had a WC above the threshold, while $52.8 \%$ of women with BMI $<25$ had a WC above the threshold. At the same time, more men $(48.6 \%)$ than women (33.3\%; p $<0.001)$ showed concordant above-threshold values for both BMI and WC. Hence, health promotion programs targeting individuals with a BMI above the threshold would miss over a third of the female population at risk. Thirdly, WC as a marker of abdominal overweight and obesity (visceral adipose tissue) has been reported to be more predictive for increased overweight-related mortality and morbidity risks, and identifies persons at increased cardiovascular risk better than the BMI $[11,13,14,36]$. However, other studies have supported the use of BMI [37], or found no differences between the predictive powers of WC and BMI [16].

For the above reasons, we used WC to identify subjects in need of weight management, i.e., to identify subjects who should reduce their weight, or who should gain no further weight. The adjusted total prevalence of subjects in need of weight management in the Swiss population was estimated to be $62.2 \%$, with more women $(66.1 \%)$ than men $(58.2 \%$; $<0.001)$ requiring weight management. The potential implications of these findings are manifold, i.e., the risk of overweight-related illnesses and the associated cost burden are much higher than previously estimated, and weight-related health promotion programs should be equally targeted at men and women.

\section{Limitations of the study}

This study had several limitations. Firstly, the sample consisted of subjects who selected themselves to be part of the study. Although we attempted to correct for known systematic sources of self-selection bias (age and gender) by applying post-stratification weightings, other, other unknown sources of self-section bias may still have been present. Secondly, the one-stage cluster sample design meant that the average design effect was quite large, especially in the case of male age cohorts with only a small number of subjects in the sample. Thirdly, the use of different measurement equipment (scales, tapes, rods) may have resulted in a greater measurement error than is generally desirable for clinical research. Finally, subjects were lightly dressed, potentially leading to slight over-estimations of WC and weight.

\section{Conclusions}

The findings of this study differ from those of previous epidemiological studies based on SHS data in several respects. This may have various implications for public health and health promotion programs. Firstly, the prevalence of subjects with above-threshold WC was higher than the prevalence of those with above-threshold BMI. These differences mean that different numbers of people would be estimated to require weight management, depending on the parameter used. For health promotion programs, it may be more appropriate to address the wider group identified by WC, which comprises subjects who should reduce their weight, or gain no further weight. Secondly, the gender differences are reversed when WC or BMI is used to identify subjects suitable for health promotion programs; the former identifies 
more eligible women than men, while the latter identifies more men than women. These differences should be taken into account in gender-specific health promotion programs.

\section{Acknowledgements \\ The authors wish to thank pharmaSuisse, the Swiss Heart Foundation, and the participating pharmacies for their efforts in collecting and providing the data for this project. A special thank you goes to Rahel Gügler for her helpful comments on earlier drafts of this paper. This study was supported by the Federal Office of Public Health (FOPH), grant number 09.002622/ 204.0001/-594}

\section{Authors' contributions}

TV contributed most of the writing and the analysis. RS and PR contributed to the writing and editorial review. All authors read and approved the final manuscript.

\section{Competing interests}

The authors declare that they have no competing interests.

Received: 3 June 2010 Accepted: 15 June 2011 Published: 15 June 2011

\section{References}

1. Schweizerische Gesundheitsbefragung 2007: Konzept, Methode, Durchführung. [http://www.bfs.admin.ch/bfs/portal/de/index/infothek/ erhebungen quellen/blank/blank/ess/03.htm].

2. Faeh D, Braun J, Bopp M: Underestimation of obesity prevalence in Switzerland: comparison of two methods for correction of self-report. Swiss Medical Weekly 2009, 139(51-52):752-756.

3. Faeh D, Marques-Vidal P, Chilero A, Bopp M: Obesity in Switzerland: do estimates depend on how body mass index has been assessed? Swiss Medical Weekly 2008, 133(13-14):204-2010.

4. Visscher TLS, Viet LA, Kroesbergen HT, Seldell Jc: Underreporting of BMI in adults and its effect on obesity prevalence estimations in the period 1998 to 2001. Obesity 2006, 14(11):2054-2063.

5. Gorber CS, Tremblay M, Moher D, Gorber B: A comparison of direct vs. self-report measures for assessing height, weight and body mass index: a systematic review. Obesity Reviews 2007, 8:307-326.

6. Taylor AW, Dal Grande E, Gill TK, Chittleborough CR: How valid are selfreported height and weigth? A comparison between CATI self-report and clinic measurements using a large cohort study. Australian and New Zealand Journal of Public Health 2006, 30(3):238-246.

7. Stommel M, Schonborn C: Accuracy and usefulness of BMI measures based on self-reported weight and height: findings from the NHANES \& NHIS 2001-2006. BMC Public Health 2009, 9:421.

8. Zhou X, Dibley MJ, Cheng Y, Ouyang X, Yan H: Validity of self-reported weight, height and resultant body mass index in Chinese adolescents and factors associated with errors in self-reports. BMC Public Health 2010, 10:190.

9. WHO: Obesity: Preventing and managing the global epidemic: report of a WHO consultation. Geneva: World Health Organisation; 2000

10. Heymsfield SB, Martin-Nguyen A, Fong TM, Gallagher D, Pietrobelli A: Body circumferences: clinical implications emerging from a new geometric model. Nutrition \& Metabolism 2008, 5(24):1-17.

11. Gus M, Fuchs SC, Moreirea LB, Moraes RS, Wiehe M, Silva AF, Albers F, Fuchs FD: Association between different measurements of obesity and the incidence of hypertension. Amcerican Journal of Hypertension 2004, 17(1):50-53.

12. Borch KH, Braekkan SK, Mathiesen EB, Njolstad I, Wilsgaard T, Stormer J, Hansen J-B: Anthropometric Measures of Obesity and Risk of Venous Thromboembolism. The Tromso Study. Arteriosclerosis, Thrombosis \& Vascular Biology 2010, 30(1):121-127.

13. Hauner $H$, Bramlage $P$, Losch $C$, Steinhagen-Thiessen $E$, Schunkert $H$, Wasem J, Jockel K-H, Moebus S: Prevalence of obesity in primary care using different anthropometric measures - Results of the German Metabolic and Cardiovascular Risk Project (GEMACS). BMC Public Health 2008, 8:282.
14. Yusuf S, Hawken S, Ounpuu S, Bautista L, FM G, Commerford P, LC C, Rumboldt Z, Onen CL, Lisheng L, et al: Obesity and the risk of myocardial infarction in 27,000 participants from 52 countries: a case-control study. Lancet 2005, 366:1640-1649.

15. Zeller M, Steg PG, Ravisy J, Lorgis L, Laurent $Y$, Sicard P, Janin-Manificat L, Beer J-C, Makki H, Lagrost A-C, et al: Relation between body mass index, waist circumference, and death after acute myocardial infarction. Circulation 2008, 118(5):482-490.

16. Ryan MC, Fenster Farin HM, Abbasi F, Feaven GM: Comparison of waist circumference versus body mass index in diagnosing metabolic syndrome and identifying apparently healthy subjects at increased risk of cardiovascular disease. American Journal of Cardiology 2008, 102(1):140-146.

17. Kuskowska-Wolk A, Karlsson P, Stolt M, Rossner S: The predictive validity of body mass index based on self-reported weight and height. International Journal of Obesity 1989, 13:441-453.

18. Plankey M, Stevens J, Flegal KM, Rust P: Prediction equations do not eliminate systematic error in self-reported body mass index. Obesity Research 1997, 5:308-314.

19. Lean ME, Han TS, Morrison CE: Waist circumference as a measure for indicating need for weight management. BMJ 1995, 311(6998):158-161.

20. Balkau B, CM A: Comment on the provisional report from the WHO consultation. European Group for the Study of Insulin Resistance (EGIR). Diabetic Medicine 1999, 16:442-443.

21. Forthofer RN, Lee ES, Hernandez M: Biostatistics. A Guide to Design, Analysis, and Discovery. Amsterdam etc.: Elsevier Academic Press; ; Second 2007.

22. Lee ES, Forthofer RN: Analyzing Complex Survey Data. Thousand Oaks: Sage; 2200671

23. Thomas D, Rao J: Small-sample comparisons of level and power for simple goodness-of-fit statistics under cluster sampling. Journal of the American Statistical Association 1987, 82(398):630-636

24. Rao J, Thomas D: Analyis of categorical response data from complex surveys: an appraisal and update. In Analysis of survey data. Edited by: Chambers R, Skinner C. New York: Wiley; 2003:85-108

25. Rao J, Scott A: On chi-squared tests for multi-way tables with cell proportions estimated from survey data. Annals of Statistiscs 1984 12:46-60.

26. Madrigal H, Sanchez-Villegas A, Martinez-Gonzalez M: Underestimation of body mass index through perceived body image as compared to selfreported body mass index in the European Union. Public Health 2000, 114:468-473.

27. Larson MR: Social desirability and self-reported weight and height. International Journal of Obesity and Related Metabolic Disorders 2000, 24:663-665.

28. Wada K, K T, Tsunekawa T, Otsuka R, Zhang H, Murata C, Nagasawa N, Matushita K, Sugiura K, Yatsuya $\mathrm{H}$, et al: Validity of self-reported height and weight in a Japanese workplace population. International Journal of Obesity 2005, 29(9):1093-1099.

29. Roberts RJ: Can self-reported data accurately describe the prevalence of overweight? Public Health 1995, 109:275-284.

30. Sebo P, Beer-Borst S, Haller DM, Bovier PA: Reliability of doctors' anthropometric measurements to detect obesity. Preventive Medicine 2008, 47(4):389-393.

31. Schneider H, Venetz W, Gallani Berardo C: Overweight and obesity in Switzerland. Part 1: Cost burden of adult obesity in 2007.Edited by: Gesundheit BzHBf. Basel: HealthEcon; 2009:.

32. Bolton-Smith C, Woodward M, Tunstall-Pedoe H, Morrison C: Accuracy ot the estimated prevalence of obesity from self-reported height and weight in an adult Scottish population. Journal of Epidemiology \& Community Health 2000, 54:143-148.

33. Oliveira A, Ramos E, Lopes C, Barros H: Self-reporting weight and height: misclassification effect on the risk estimates for acute myocardial infarction. European Journal of Public Health 2009, 19(5):548-553.

34. Hauner H, Bramlage $P$, Lösch C, Jöckel K-H, Moebus S, Schunkert H, Wasem J: Overweight, obesity and high waist circumference: regional differences in prevalence in primary medical care. Deutsches Ärzteblatt international 2008, 105(48):827-833.

35. García-Álvarez A, Serra-Majem L, Ribas-Barba L, Castell C, Foz M, Uauy R, Plasencia A, Salleras L: Obesity and overweight trends in Catalonia, Spain 
(1992-2003):gender and socio-economic determinants. Public Health Nutrition 2007, 10(11(A)):1368-1378.

36. Han TS, van Leer EM, Seidell JC, Lean ME: Waist circumference action levels in the identification of cardiovascular risk factors: prevalence study in a random sample. BMJ 1995, 311(7017):1401-1405.

37. Gosh JR, Bandyopadhyay AR: Comparative evaluation of obesity measures: relationship with blood pressures and hypertension. Singapore Medical Journal 2007, 48(3):232-235.

\section{Pre-publication history}

The pre-publication history for this paper can be accessed here:

http://www.biomedcentral.com/1471-2458/11/473/prepub

doi:10.1186/1471-2458-11-473

Cite this article as: Volken et al: Need for weight management in

Switzerland: findings from National Blood Pressure Week 2009. BMC

Public Health 2011 11:473.

Submit your next manuscript to BioMed Central and take full advantage of:

- Convenient online submission

- Thorough peer review

- No space constraints or color figure charges

- Immediate publication on acceptance

- Inclusion in PubMed, CAS, Scopus and Google Scholar

- Research which is freely available for redistribution

Submit your manuscript at www.biomedcentral.com/submit 